\title{
Brain-Computer Interface and Human Rights
}

\author{
${ }^{1}$ Matej Kostrec, ${ }^{2}$ Bohumír Štědroň \\ ${ }^{1}$ Academy of the Police Force in Bratislava, Slovakia \\ ${ }^{2}$ Charles University Prague \\ ${ }^{1}$ matej.kostreceakademiapz.sk, ${ }^{2}$ stedron@seznam.cz
}

\begin{abstract}
Information and communication technologies are part of every area of our lives. They help us to facilitate not only physical activities, but they are also a means of revealing and uncovering the secrets and connections of human organisms, thinking, decision-making and processes that are associated with psychic and mental activities. The aim of this article is to present one of the information technologies, namely neuro-technology, whose mission is to scan, read and analyze electromagnetic signals from the brain using computer means. For this purpose, various devices are used, which we classify in the category of BrainComputer Interface. They are used to map thought processes, which are then used in practice in medicine, the judiciary, but also in marketing and entertainment. Data taken from the brain of a human being belong to sensitive data, and it is therefore necessary to protect them through human rights legislation.
\end{abstract}

Keywords: Brain-Computer Interface, human rights, neuro imaging, neuro-law, neuro-technology, neuro-science, medicine, judiciary, brain activity imaging, cognitive freedom, mental confidentiality, mental integrity, psychological continuity.

\section{$1 \quad$ Introduction}

The boundaries of the skull have long been considered the dividing line between the observable and undetectable dimension of a living human being. Although the primitive forms of neurosurgery used in ancient societies may have allowed the observation and even manipulation of brain tissue, neural and mental processes, basic emotions, reasoning, and behavior remained intact.

However, modern advances in neuroscience and neuro-technology have gradually unlocked the human brain and made it possible to understand the processes in the brain as well as their connection to observable mental states and behaviors. In 1878, Richard Canton was the first to discover the transmission of electrical signals through an animal's brain. ${ }^{1}$

Forty years later, the first human electroencephalography (EEG) was recorded. Since then, a neuro-technical revolution has taken place not only in medicine but also outside

1 Available on: https://up-magazine.info/le-vivant/neurosciences/6642-face-aux-neurotechnologies-de-nouveaux- droits-de-l-homme-s-averent-necessaires/ 
it. In the 1990s, sometimes referred to as the "Decade of the Brain," the use of imaging techniques for neurobehavioral studies increased dramatically. Today, a wide range of imaging technologies is already available on the market. For example, non-invasive recording and imaging of brain activity models, often associated with performing physical or cognitive tasks, has become common practice.

Another technique, such as functional magnetic resonance imaging (MRI), indirectly measures the electrical activity of the brain, using hemodynamic responses (blood flow in the brain) as indirect indicators. Current MR imaging techniques can locate brain activity, graphically display models of brain activation, and determine the intensity of activation force by color coding. MRI techniques are used for a variety of purposes, including pre-surgery risk assessment and functional mapping of areas of the brain to observe recovery from stroke or post-surgery. In addition, a variety of neurological conditions, including depression and Alzheimer's disease, can currently be diagnosed with MRI.

The ability of neuro-imaging techniques to map brain function has also been effectively tested to gain an idea of people's intentions, opinions and attitudes. Brain scanning not only allows to "read" specific intentions and memories related to experience, but it even seems to be able to decode more general preferences. One US study showed that RMI analyzes can be used to successfully identify political views by identifying functional differences in the brains of Democrats and Republicans. Similarly, the frequent preference for sports cars in men is related to specific functional differences in the brains of men compared to the brains of women. ${ }^{2}$

\section{Brain-Computer Interface}

The Brain-Computer Interface (BCI) is a direct connection between the brain and the computer that allows an individual to perform tasks without the action of peripheral nerves and muscles. This type of device allows you to control a computer, prosthesis or any other automated system without the need for his hands or feet. The concept dates back to 1973, and the first human experiments date back to the mid-1990s. ${ }^{3}$

Brain-machine interfaces (BCIs) are being developed in various laboratories around the world in the form of devices that should enable people with severe disabilities to gain some autonomy. For example, individuals who have Quadruple Heart Syndrome or Locked Syndrome (although the patient thinks but can only move the eyelids) can control the robotic exoskeleton ${ }^{4}$ through thought movement. People with limb

2 Available on: https://up-magazine.info/le-vivant/neurosciences/6642-face-aux-neurotechnologies-de-nouveaux- droits-de-1-homme-s-averent-necessaires/

3 Available on: https://www.inserm.fr/information-en-sante/dossiers-information/interfacecerveau-machine-icm

4 A robotic exoskeleton is a device designed to support human muscles while walking or working, for example for medical purposes. It consists of an outer frame (skeleton), which is controlled by man using hydraulics and motors. At the University of Michigan, a device has been developed that can be used for rehabilitation purposes for patients after a stroke, traffic accidents, or simply where there is a need to restore limb function. It is relatively simple to use, the device senses the 
amputations can control the movements of their prosthesis by thinking, and people who have lost speech could speak through a computer, always only through thoughts (action by thought). Other applications of BCI technology can also be used in healthy people, for example in the field of video games.

How does BCI work? The structure of the BCI includes a system for obtaining and processing brain signals, a system for classifying and subsequently transmitting these signals to the control (writing on the screen, movement of a wheelchair or prosthesis, etc.). Specifically, the user focuses his attention on external stimulation of his choice or imagines performing a movement. It generates characteristic and measurable brain activity using sensors. These signals are transmitted to a computer, which analyzes them to extract useful data from them, and then transforms them into machine commands (prosthesis, exoskeleton, wheelchair, software interface, artificial voice, etc.).

These systems most often operate in a closed loop (or feedback loop), allowing the user to progress in mastering $\mathrm{BCI}$ technology. The user monitors the result of his brain command, then adjusts his thoughts and gradually improves the accuracy of the action that the system creates.

The research is also inspired by machine learning algorithms that make the machine adaptive and able to improve the interpretation of the user's brain activities over time.

Using these interfaces is not always intuitive and the adaptation and learning phase can be long to master the tool. Some studies estimate that the proportion of the population that cannot successfully manage current systems could reach $30 \%$. This partly explains why, despite recent advances in this area of research, these applications are not yet available on the market.

nerve signals sent by the brain, which determine which muscle to contract, stretch, how much, where, and so on. These signals are then received by the device itself and moved by means of piston cylinders by means of these "commands".

Available on: Cyberdyne's robot suit HAL to keep people walking [online]. Japan: YouTube (The Japan Times), 2014-07-13, rev. 13. 7. 2014 [cit. 2020-03-30] 


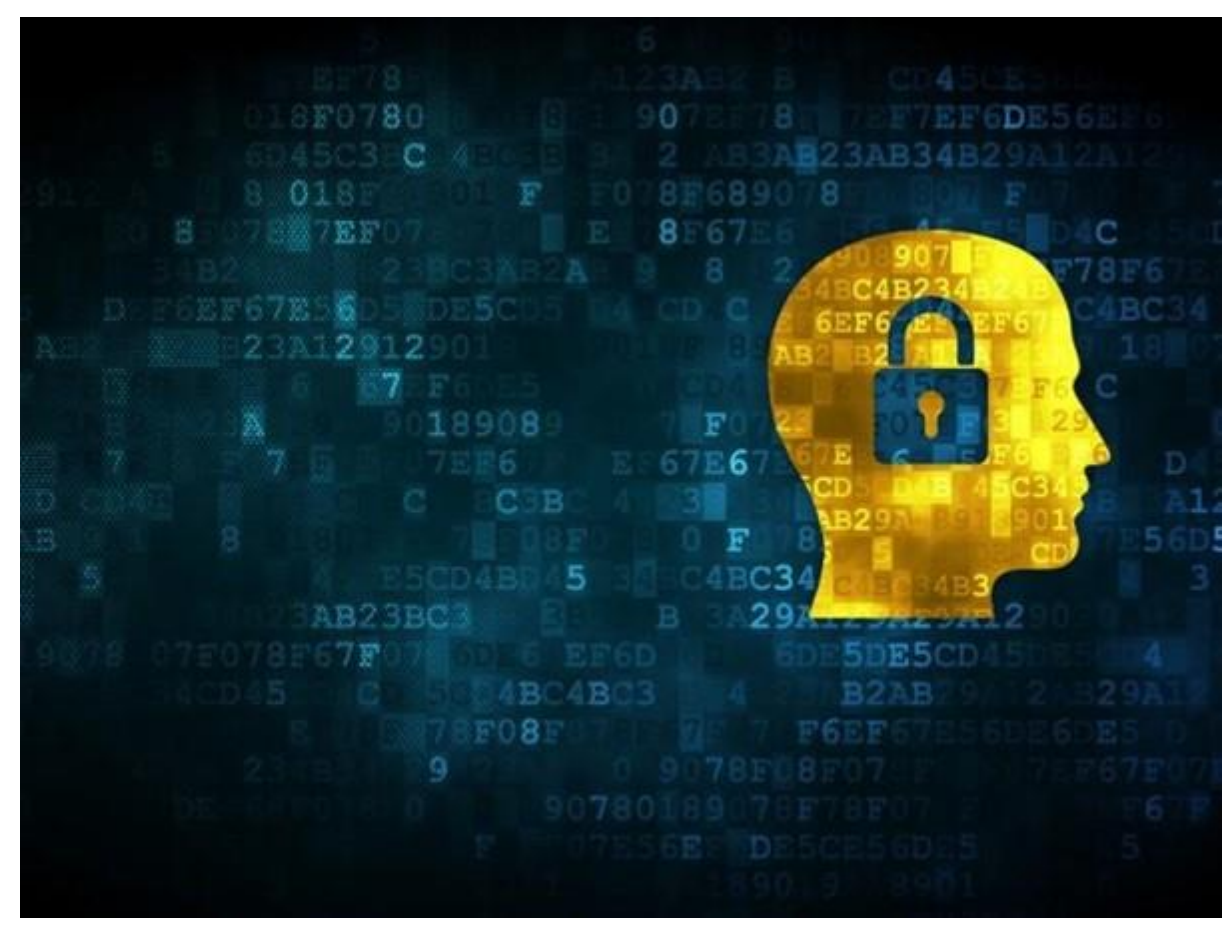

Fig. 1. Protection of data captured from the brain. Available on: https://www.silicon.fr/wp-content/uploads/2015/06/Cerveau-mot-de-passe-684x513.jpg

\subsection{Recording of electrical signals}

The first step in triggering BCI is to record brain activity. Most often, electrodes are placed on the skull, cortex, or directly in the brain to record electrical signals emitted by neurons during a particular mindset.

There are three ways to record:

1. Invasive - An electrode grid is implanted in the cortex, which records signals from a population of neurons with high spatial accuracy. This method is associated with the risk of complications and loss of signal in the longer term. To date, it has only been tested in a very small number of volunteer patients in the United States.

2. Semi-invasive - Under the dura mater, the membrane that surrounds the brain just below the skull, is placed a grid of electrodes. Spatial resolution is slightly less good than for implantation in the cortex, but the risks of complications are lower and can be used quickly in medicine.

3. Non-invasive - The patient is wearing an electric helmet equipped with multiple electrodes for measuring the electroencephalogram (EEG). Spatial resolution is limited, and the recording time does not exceed one day. However, this system is cheap, easy to use and allows you to predict many applications, even for the general public. In fact, it is the most widely used recording mode today. 
The choice of recording method depends on the desired destination and application. In all cases, the electrodes can be removed in the event of a problem.

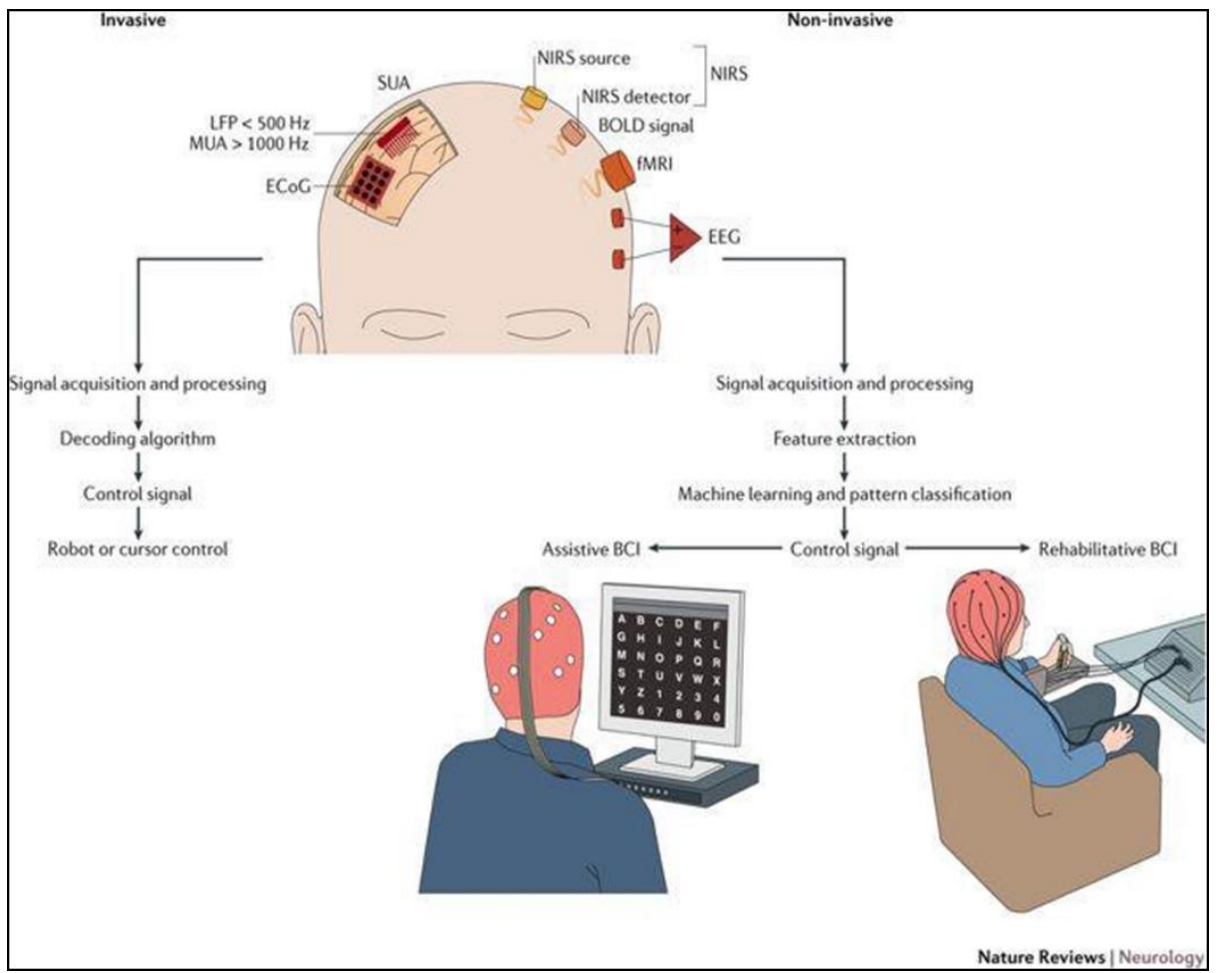

Fig. 2. Invasive vs. non-invasive BCI Source: Chaudhary U., Birbaumer N., Ramos-Murguialday A., Brain-computer interfaces for communication and rehabilitation, Nature Reviews Neurology $12,513-525(2016)$

\subsection{Signal interpretation software}

The electrodes used for recording are connected to external software that classifies, analyzes and interprets brain signals and then issues them in the form of commands, which are then executed by a controlled machine.

Depending on the task to be performed with the BCI, numerous brain signals are recorded which are not easy to process. The analysis takes into account several dimensions, namely the duration of signals, their frequency and their distribution in space. Pre-processing and filtering are used to remove recorded background noise signals. The signal characterizing the intention is then extracted and its components are classified to store only useful information. 


\subsection{Medical applications of BCI}

Numerous research teams are working to develop BCIs for handling exoskeletons support devices for people who are completely paralyzed to help them get up, move and perform various movements. However, there are many other applications, such as controlling a wheelchair or limb prosthesis or a computer to speak or write.

In France, researchers have developed a BCI that allows you to write using thought selection of letters presented on a screen. The rows and columns of letters are displayed in sequence on the screen, and when the desired letter appears, the person in question focuses his attention on it. The software knows how to interpret the brain signals transmitted by this person and selects the appropriate letter when the concentration ceases.

The feedback generated by the BCI can allow the user to be aware of their brain activity, and to try to learn to control it. This is a general principle of biofeedback or neurofeedback when applied to the brain. In addition to treatment approaches for psychiatric disorders, this principle could also lead to new therapeutic approaches, in particular to reduce attention deficit disorder. The researchers plan to start clinical trials to evaluate the effect of biofeedback and neurofeedback in children with attention deficit disorder.

\subsection{Another direction of BCI development}

One of the goals of the brain-machine interface is to restore the function of a person lost after an accident. Whether it is a resumption of leg or shoulder use after spinal cord injury or an improvement in gait in patients with Parkinson's disease, or other incurable diagnoses. What do the words "brain-machine interface" mean? Is it literally the connection between the brain and the electronics and the establishment of a dialogue between these entities in order to remedy the loss of function?

The current challenges for researchers are to improve the biocompatibility and integration of implants into the brain. Currently available invasive electrode networks are not biocompatible. After implantation into the cortex, they elicit a tissue defense response. Glial cells encapsulate the implant, which after a while results in a loss of signal. Using nanotechnologies and specific materials such as diamond or graphene, scientists are trying to make this type of device symbiotic with the cerebral cortex. In addition, current devices amplify signals received remotely, creating background noise that affects the quality of recording processing. Scientists are working to improve the integration of electrodes in the cortex. One of the projects is the development of flexible electrodes that would be built into the brain using biodegradable microneedles. At the same time, research teams continue to work on electrode miniaturization.

This research will only be of clinical relevance if it improves the daily lives of people with disabilities. The ultimate goal is, in addition to the technological prowess represented by the possibility of piloting an object with an idea, also the requirement that these people can finally move and communicate independently and be independent. For this reason, improvements in implants and brain signal processing software must also 
be accompanied by improvements in the tools provided to patients, such as a complete exoskeleton for quadriplegic ${ }^{5}$ people.

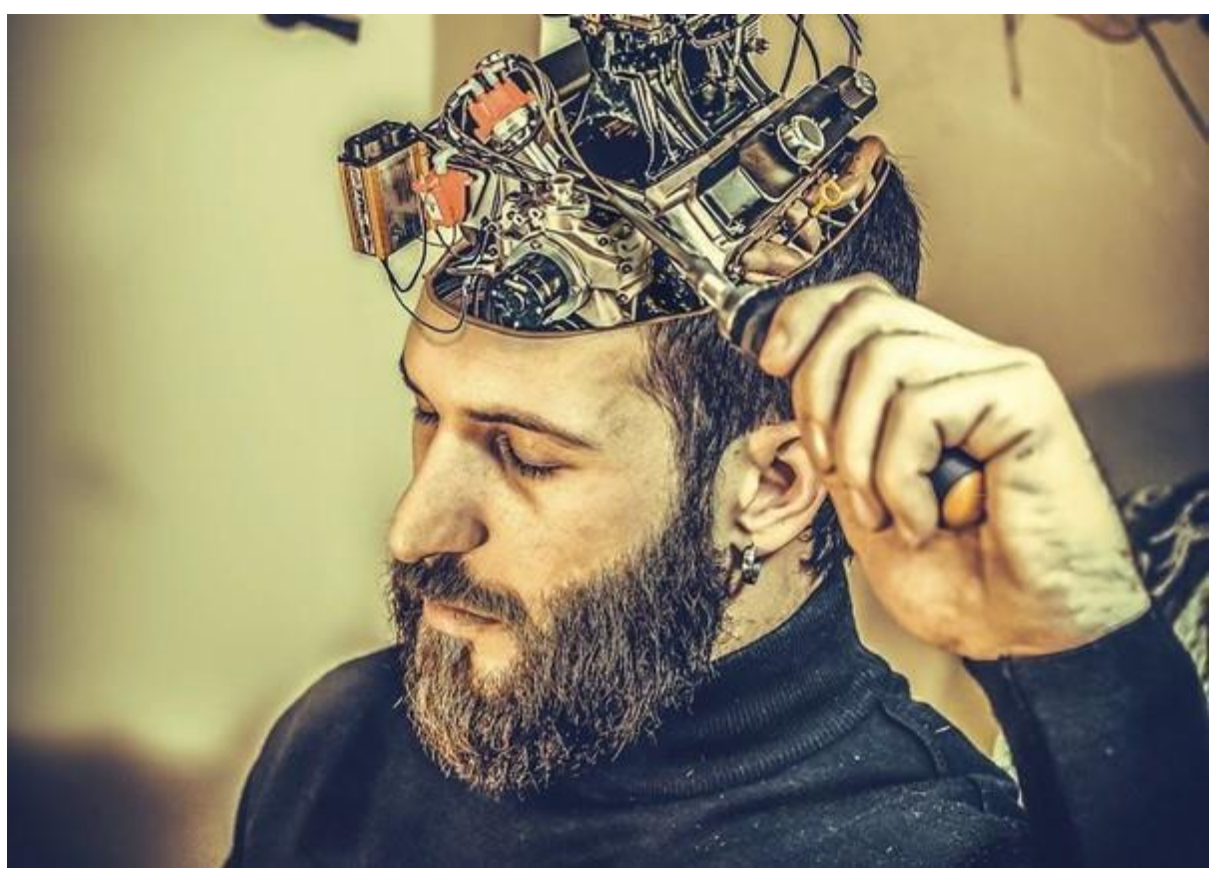

Fig. 3. One of the scanning devices Available on: https://images.theconversation.com/files/232268/original/file-20180816-2915-22qkrf.jpg?ixlib=rb$1.1 .0 \&$ rect $=0 \% 2 \mathrm{C} 399 \% 2 \mathrm{C} 1920 \% 2 \mathrm{C} 1362 \& \mathrm{q}=45 \&$ auto $=$ format $\& \mathrm{w}=926 \&$ fit $=$ clip

\subsection{New ethical dilemmas for the use of BCI}

These new human-machine interfaces raise many ethical questions. How to guarantee equal treatment of these devices for all patients due to their foreseeable high costs and difficulties of access? How to distinguish human responsibility from machine responsibility in case of BCI failure? Does neurofeedback have side effects and can we imagine systems that would adversely affect the brain? Scientists are already asking such questions and discussing them outside their communities. These issues, which could become increasingly urgent, call for clear rules and recommendations on what is ethically acceptable and what is not. ${ }^{6}$ Therefore, it is important to address the impact of

5 Quadruplegia is the complete or partial paralysis of all four limbs and torso, caused by damage to the spinal cord in the lower neck area. Available on: http://www.apparelyzed.com/quadriplegia.html [cit. 2020-04-10]

6 Available on: https://theconversation.com/linterface-cerveau-machine-un-dialogue-pourreparer-le-corps- 
the use of BCI technologies on the human individual and the protection of his identity and privacy.

\subsection{Neuro-technologies require a revision of human rights legislation}

The development of brain imaging tools and sophisticated brain-computer interfaces shifts these technologies from clinical trials in the medical environment to practical and general applications. There is therefore a risk of misuse of technology, which poses an unprecedented threat to an individual's personal freedom. We can document this with the following examples:

- Assess the criminal liability or risk of recidivism of a criminal using the BCI tool.

- Using brain imaging for neuro-marketing to understand consumer behavior and elicit desired customer responses.

- Translate brain waves into pictures, texts, or sounds.

- Hacking a computer with data read from the brain and allowing a third party to listen to someone's thinking.

At present, international human rights law makes no specific reference to neurotechnologies or neuroscience. The activities associated with the proposal to innovate legislative texts in this area are also so far rare.

Two Swiss scientists, in their contribution to the scientific journal Life Sciences, Society and Policy ${ }^{7}$, are calling for the creation of "neuro-laws" to protect individuals from the development of neuroscience and neuro-technology. The Neuro-ethics specialist at the University of Basel, Marcello Lenca, and Roberto Anderno, a human rights lawyer at the University of Zurich, suggested to incorporate elements of the human mind into human rights to protect them from rapid advances in artificial intelligence. ${ }^{8}$ Indeed, the express advancement of neuroscience development provides unprecedented access to data from the human brain. There are various techniques practiced in this field

101558 ?utm_term=Autofeed\&utm_campaign=Echobox\&utm_medium=Social\&utm_source=Twitter\#Echobox= 1534770778 [cit. 2020-02-23]

7 The aim of this scientific journal is to analyze the social, ethical and legal dimensions of the most dynamic life of biological sciences and technology sectors and to discuss ways to support innovation, sustainable development and user-centered social policies. Life Sciences, Society and Policy provides an academic forum for contributions to the intersections of life sciences, philosophy, bioethics, scientific studies and policy research, and covers a wide range of research in both emerging and applied research areas. Its citation impact is: 1.222 - Source Normalized Impact per Paper (SNIP), 0.562 - SCImago Journal Rank (SJR), 2.020 - CiteScore. Available on: https://lsspjournal.biomedcentral.com/ [cit. 2020-02-15]

8 Available on: https://www.silicon.fr/face-au-hacking-du-cerveau-de-nouveaux-droits-delhomme-173491.html 
on human subjects. These include, for example, neuroimaging ${ }^{9}$, neuro-stimulators ${ }^{10}$ and the use of brain-computer interfaces for various purposes, such as medical, marketing and even military.

Both scientists justify the need to create a new kind of human rights called "neurolaw" by the speed of use and the growth of technologies to study the functioning of the brain. Methods of "reading" data from the brain of a human individual raise legal, ethical, and social challenges that can "force the reconceptualization of certain human rights". ${ }^{11} 11$ In their contribution, they state at least 4 rights:

- the right to cognitive freedom ${ }^{12}$,

- the right to intellectual confidentiality, ${ }^{13}$

- the right to mental integrity, ${ }^{14}$

- the right to psychological continuity ${ }^{15}$.

People with mental disorders have the right to keep information about themselves and their illness confidential. Cognitive freedom refers to the right of individuals to choose whether or not to use neuro-technologies. No person can be forced to use these technologies. This right should ensure that no one can change an individual's mental state. In particular, this right could be applied in cases of brain stimulation, which is

9 Neuroimaging is a set of techniques and methods for imaging the structure and functionality of the brain. Available on: https://www.fil.ion.ucl.ac.uk/ wpenny/mbi/ [cit. 2020-02-01]

10 Spinal cord neurostimulation or spinal cord neuromodulation are techniques used to treat certain chronic pain.

11 Available on: https://www.silicon.fr/face-au-hacking-du-cerveau-de-nouveaux-droits-delhomme-173491.html

12 Cognitive freedom or the right to mental self-determination is part of the rights and freedoms to control one's own knowledge and consciousness. It is an extension of the basic principle of freedom of thought. Although a term defined relatively recently, it is increasingly supported by technological advances in neuroscience that allow and will continue to allow direct influence on human consciousness and cognitive processes.

13 People with mental disorders have the right to keep information about themselves and their illness confidential. Available on:https://apps.who.int/bookorders/anglais/detart1.jsp?sesslan $=1 \& \operatorname{codlan}=2 \& \operatorname{cod} \operatorname{col}=15 \& \operatorname{cod} c \mathrm{ch}=611$

1414 In the context of medicine and biology, the following facts must be respected in the context of this peacock:

a) the free and informed consent of the person concerned in accordance with the procedures laid down by law;

b) the prohibition of eugenic practices, in particular those aimed at selecting people to improve the gene pool;

c) the prohibition of making the human body and its parts a source of profit;

d) a ban on the reproductive cloning of humans.

Available on: https://fra.europa.eu/fr/eu-charter/article/3-droit-lintegrite-de-la-personne

15 It is the patient's right, for example, that after brain surgery, during which a series of gradual changes take place in the brain, the patient is psychologically the same person and not someone else, such as Napoleon. Available on: https://dspace5.zcu.cz/bitstream/11025/26770/1/Jakub\%20Sestak\%20BC\%20final.pdf 
used to help restore memory. The purpose of recognizing such a right would be to prevent the harmful intent of potential brain hackers.

The right to intellectual confidentiality requires an extension of the right to privacy and the protection of brain activity data. Under this right, it would be illegal to "read the thoughts" of an individual or to use data from his brain without his consent. In the United States, for example, in November 2016, the military performed brain stimulation on some of its employees. Its goal was to improve their cognitive performance. Recognition of these rights would, according to scientists, allow employees who are under pressure from their hierarchy to refuse to participate in these experiments, the long-term impact of which remains unknown. ${ }^{16}$

The right to preserve mental integrity must be exercised in particular when using the brain- machine interface. Research teams are working on non-invasive sensors to decipher ideas. Test prototypes should already be available for testing. In the same vein, other scientific teams are working on the possibility of implanting artificial intelligence directly into the human brain. However, there is a concern that these interfaces will be manipulated and misused for malicious purposes. Therefore, it is necessary to protect the mental integrity of people. The aim of recognizing such a right should be to prevent potential brain hackers from malicious harm. This idea may sound futuristic, but brain implants have become popular already today. For example, a brain chip that makes a person smarter, improves memory, fights tics or fights depression, while its other uses are constantly growing. Anything is possible in this area as long as the hacker who controls the chip can change the area of the brain and cause cognitive impairment.

The right to psychological continuity refers to an individual's ability to maintain a personal identity even after changes made to his or her brain by third parties. These are in particular certain therapeutic applications based on intracranial ${ }^{17}$ stimulations. In this context, the consent of the person concerned to such an intervention will be mandatory, as will the maintenance and protection of essential nerve functions. The purpose of this right is to protect the identity of individuals by prohibiting any intrusion into their brains that would affect their individual consciousness. This is especially true of medical practices known as deep brain stimulation, during which electrodes are implanted under the skin or into the human brain to deliver electric shocks and treat diseases such as Parkinson's disease, Alzheimer's disease or even anorexia. They are considered to be effective even though their effects on the patient are not fully known. More than half of Alzheimer's patients said after treatment that "I no longer feel like myself", "I feel like

Available on: Marcello Ienca et Roberto Andorno, " Towards new human rights in the age of neuroscience and neurotechnology », Life Sciences, Society and Policy, vol. 13, 26 avril 2017 (ISSN 2195-7819, PMID 28444626, PMCID 5447561, DOI 10.1186/s40504-017-0050-1, online [archive]

16 Available on: https://www.france24.com/fr/20170427-face-developpement-neurotechnologies-chercheurs- defendent-reconnaissance-nouveaux-droits-fondamentau

17 Intracranial stimulation is the stimulation of a brain region by direct application of an electric current through implanted electrodes. 
a robot" or "I didn't find myself again after surgery"18. The right to psychological continuity would protect subjects from treatment that could damage their sense of identity.

\subsection{Brain and law - analysis of the origin of neuro-law}

System of Indictment actions, in which the expert plays a major role in interpreting scientific evidences, has facilitated the entry of science into American courts and the courts of the Commonwealth countries. In this way, neuroscience has entered courts in the United States, Canada and Israel more than 35 years ago, through anatomical scanners, mainly as evidence of defense. One of the best-known cases is the case of John Hinckley, who tried to assassinate President Reagan in 1981. The defense brought as evidence a brain scan that showed an atrophied area indicating that Hinckley was suffering from schizophrenia. However, the term neuro-law appeared in 1991 and its originator is considered to be the scientist and lawyer of J. Sherrod Taylor. In fact, it is associated with the dynamic development of neuroscience, supported by the development of functional magnetic resonance imaging (MRI) in the 1990s. Like the terms for its sister disciplines - neuro-theology, neuro-economics and neuro-ethics that appeared around 2000, or neuro-philosophy dating back to 1986 - the term neuro-law has emerged as an area of application to the knowledge gained from brain function to elucidate new criminal and antisocial behavior, and thus a new criminology. In fact, neuro-law, by its radical treatment of fundamental questions of determinism and free will, would call into question classical judicial notions of crime and punishment. ${ }^{19}$

In the United States, neologism "neuro-law" refers to activities that examine the use of neuro- science in the forensic sciences to shed new light on the use of neuro-science at various stages of the court proceedings, as well as on what can lead individuals to break the law.

The research network in law and neuroscience, supported by the John D. and Catherine T. MacArthur Foundation, focuses on a set of closely related issues at the intersection of neuroscience and criminal justice. Its objectives include: "To assist the justice system in preventing the misuse of neuro-scientific evidences in the context of criminal law" and "to explore ways to develop knowledge in neuroscience in order to improve the fairness and efficiency of the justice system."20

In fact, the goals of neuro-law are simultaneously repressive (confusing criminals), preventive (determining the danger of the individual) and therapeutic (developing methods of treatment).

18 It is featured on the Gizmodo website in the article Proposed Human Rights Would Protect Your Mind. (Gizmodo is a website dedicated to design, technology, science and science fiction). Available on: https://gizmodo.com/proposed-human-rights-would-protect-your-mindfrom-the-1794690549

19 Resource: DARTIGUES Laurent: Une irrésistible ascension ? Le neurodroit face à ses critiques. In: Zilsel 2018/1 (N 3), p 63 - 103. Available on: https://www.cairn.info/revue-zilsel2018-1-page-63.htm?try_download=1

20 Available on: https://www.lawneuro.org/mission.php 


\section{Conclusion}

It may seem a little early to define these rights, principles and rules, when all the technologies involved are still at an early experimental stage. Let us not forget, however, that no basic guidelines have been set for neutralizing the impact of using BCI devices on human before many corporations have invested large amounts of money and capacity in neuro-technology, and this does not seem to work in practice unless it will not comply with current legislation adopted in the field of human rights protection. However, this is not yet in line, and it is therefore necessary to start adopting new human rights as soon as possible.

So far, we must make a clear distinction between the various approaches, all of which are interested in the autonomy of the patient with the least visible material for achieving a better social life. These research activities are making great progresses and we can hope that their results will be available in hospitals in the next ten years at the latest. Until then, it is necessary to update the relevant legislative frameworks and provisions.

It should be borne in mind in this update that the principle of non-discrimination between individuals solely on the basis of neuro-biological data must be at the heart of any scientific, institutional and neuro-biological approach dealing with the use of neuro-science, especially bioethics, even if that approach has not yet been included in the latest version of the bioethics act.

In older scientific disciplines, such as medicine, economics, psychology or sociology, the results applied to these disciplines of the brain sciences will be useful if they are compared with other areas of research and supplemented by other observations.

It is certainly not possible to question the fact that the desire of every individual on our planet is for the development of neuro-sciences and neuro-technologies to advance, while its main goal must remain respect for applicable laws and human dignity.

\section{Acknowledgements}

This research was supported and funded by APVV-17-0656 titled Transformation of Paradigm in Management of Organizations in the Context of Industry 4.0.

\section{Resources:}

Monographs and articles:

1. CLERC, Maureen, BOUGRAIN, Laurent and LOTTE, Fabien: Brain-computer interfaces, 2, Technology and applications (Cognitive Science). Editor: Wiley-ISTE, London, 2016. 364 p. ISBN 978- 1-848-21963-2

2. CLERC, Maureen, BOUGRAIN, Laurent and LOTTE, Fabien: Brain-computer interfaces 1: Methods and perspectives (Cognitive Science). Editor: Wiley-ISTE, London, 2016. 330 p. ISBN 978-1-848-21826-0

3. DARTIGUES Laurent: Une irrésistible ascension ? Le neurodroit face à ses critiques. In: Zilsel 2018/1 (N³), p. 63 - 103. Available on: https://www.cairn.info/revue-zilsel- 20181-page-63.htm?try_download=1 
4. HALADOVÁ Eva, NECHVÁTALOVÁ Ludmila: Vyšetřovací metody hybného systému. Editor: Národní centrum ošetřovatelství a nelékařských zdravotnických oborů, Brno 2010, 135 p. ISBN 978-80-7013-516-7.

5. KRAJČA, Vladimír, MOHYLOVÁ Jitka: Číslicové zpracování neurofyziologických signálů. Editor: Česká technika - nakladatelství ČVUT, 2011. 167 p., ISBN 978-80-0104721-7.

6. PÁNEK, David.: Elektroencefalografické koreláty pohybového chování a výkonnostní zátěže. Editor: Univerzita Karlova, nakladatelství Karolinum, Praha 2016. 105 p. ISBN 97880-246-3435-7.

7. RICHMOND Sarah, REES Geraint, and EDWARDS Sarah: I Know What You're Thinking: Brain imaging and mental privacy. Editor: Oxford University Press 2012. 288 p. ISBN 9780199596492

8. ŠILHAVÝ Radek, ŠILHAVÝ Petr, PROKOPOVÁ Zdenka: Cybernetics Approaches in Intelligent Systems. Editor: Springer 2017. 408 p. ISBN 978-3319676173

9. ŽÁK, Roman. Zpracování mozkové aktivity v Bci systémech, In: Trilobit 1/2012, Editor: Univerzita Tomáše Bati ve Zlíně, ISSN: 1804-1795

10. ŽÁK, Roman: ̌̌ízení systémů pomocí aktivizace mozkových center. Editor: Univerzita Tomáše Bati ve Zlíně, 2013. 61 p. ISBN 978-80-7454-685-3

\section{Internet Resource:}

.

11. http://archives.strategie.gouv.fr/cas/system/files/cas-dqs_dt-_ neurodroit_11septembrereduit_0.pdf

12. http://paris-singularity.fr/in-a-neurotechnology-future-human-rights-laws-will-need-to-berevisited/

13. https://apps.who.int/bookorders/anglais/detart1.jsp?sesslan=1\&codlan=2\&codcol $=15 \& \operatorname{codcch}$

14. $=611$

15. https://dspace5.zcu.cz/bitstream/11025/26770/1/Jakub\%20Sestak\%20BC\%20final.pdf https://fra.europa.eu/fr/eu-charter/article/3-droit-lintegrite-de-la-personne https://gizmodo.com/proposed-human-rights-would-protect-your-mind-from-the-1794690549

16. https://theconversation.com/linterface-cerveau-machine-un-dialogue-pour-reparer-lecorps- $\quad 101558$ ?utm_term=Autofeed\&utm_campaign=Echobox\&utm_medium=Social\&utm_source=

17. Twitter\#Echobox $=1534770778$

18. https://up-magazine.info/le-vivant/neurosciences/6642-face-aux-neurotechnologies-denouveaux-droits-de-1-homme-s-averent-necessaires/

19. https://www.cairn.info/revue-zilsel-2018-1-page-63.htm?try_download=1

20. https://www.france24.com/fr/20170427-face-developpement-neurotechnologies-chercheurs- defendent-reconnaissance-nouveaux-droits-fondamentau

21. https://www.inserm.fr/information-en-sante/dossiers-information/interface-cerveau-machine- icm

22. https://www.lawneuro.org/mission.php

23. https://www.silicon.fr/face-au-hacking-du-cerveau-de-nouveaux-droits-de-lhomme173491.html 